\title{
Proximal aortic aneurysms in patients with conotruncal anomalies: Size matters...but so do other things
}

\author{
Harold M. Burkhart, MD, Jess L. Thompson, MD, and Sabrina D. Phillips, MD
}

\author{
From the Division of Cardiovascular and Thoracic Surgery, University of Oklahoma Health Sciences Center, \\ Oklahoma City, Okla. \\ Disclosures: Authors have nothing to disclose with regard to commercial support. \\ Received for publication Feb 1, 2017; accepted for publication Feb 6, 2017; available ahead of print March 6, \\ 2017. \\ Address for reprints: Harold M. Burkhart, MD, Division of Cardiovascular and Thoracic Surgery, University of \\ Oklahoma Health Sciences Center, 800 Stanton L. Young Blvd AAT-9000, Oklahoma City, OK 73104 (E-mail: \\ Harold-burkhart@ouhsc.edu). \\ J Thorac Cardiovasc Surg 2017;154:210-1 \\ 0022-5223/\$36.00 \\ Copyright $\subset 2017$ by The American Association for Thoracic Surgery \\ http://dx.doi.org/10.1016/j.jtcvs.2017.02.004
}

"All's well that ends well"

— William Shakespeare

Two decades ago, Coady and colleagues ${ }^{1}$ published their seminal article regarding the appropriate aortic size for thoracic aortic aneurysm (TAA) surgical intervention in the Journal of Thoracic and Cardiovascular Surgery. At that time, much had been published on how to do TAA operations, but little was available about the natural history and timing of intervention. They found that the hinge point for complications (dissection or rupture) of an ascending aortic aneurysm was a size of $6 \mathrm{~cm}$. This led to recommending surgical intervention for asymptomatic proximal aortic aneurysms at $5.5 \mathrm{~cm}$. Importantly, they pointed out that age of patient and coexisting disease, as well as the experience of the surgical team should all have a bearing on the decision to operate.

Twenty years later, in this issue of the Journal, Dr Vricella ${ }^{2}$ has provided the readership with an excellent review of the key articles supporting the current advice for surgical intervention in nonsyndromic subsets of patients with proximal TAA. The subsets include those with a bicuspid aortic valve (BAV), nonsyndromic young patients with inherited TAA, and patients with root aneurysms after repair of congenital conotruncal anomalies. A strong argument is presented for surgical intervention at $5 \mathrm{~cm}$ in patients with BAV with a family history of dissection or a growth rate of $0.5 \mathrm{~cm}$ per year. Patients with nonsyndromic TAA are discussed in detail and the literature presented supports a more aggressive timeline to surgery. With regard to the patients with conotruncal TAA, he points out the rarity of proximal aortic complications as well as the limited data and advocates a more conservative approach.

As physicians who treat adult congenital cardiac patients, this latter subset is of particular interest. As noted, it is not uncommon for patients with conotruncal anomalies to have early dilation of the proximal aortic root. Theories for this enlargement include increased aortic blood flow before

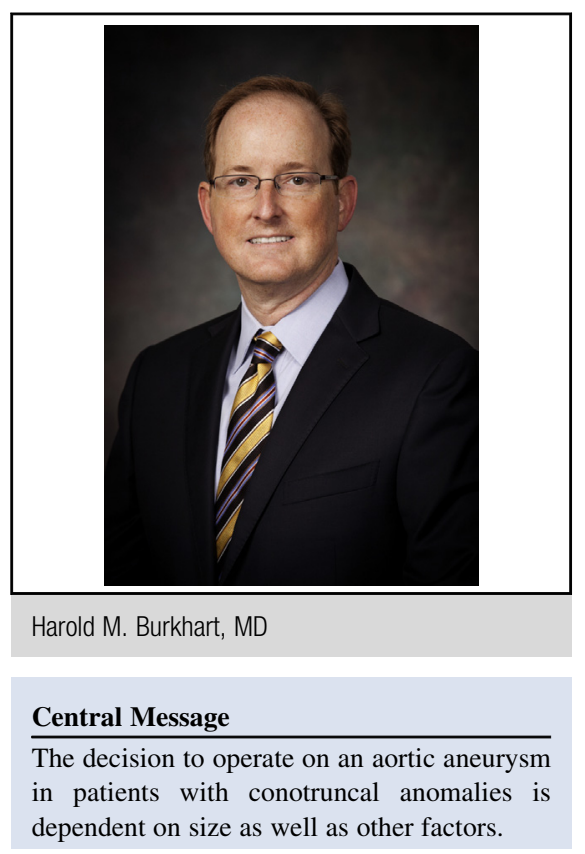

See Article page 207.

complete repair and intrinsic vascular structural abnormalities. $^{3}$ This preexisting dilation is just one of several issues that support a more conservative approach to patients with conotruncal anomalies. It is important to remember that these patients have often had multiple cardiac operations. Performing an aortic root replacement in an adult patient with multi-redo congenital cardiac anomalies is likely associated with a greater surgical risk than patients with nonconotruncal anomalies. Surgical concerns include not only when to operate for aortic enlargement, but more commonly, should the aorta be addressed at the time of operation for another issue, such as pulmonary valve replacement or pulmonary artery reconstruction. Adding an aortic root replacement to a low-risk pulmonary valve replacement in a patient with tetralogy of Fallot certainly adds to the risk. Whether or not adhesions related to multiple cardiac operations is protective is up for debate. Furthermore, the fact that so very few dissections or ruptures have been reported, despite the high number of currently living adult patients with conotruncal anomalies, makes it hard to support an aggressive tactic. Other factors that may play a role in the decision making include aortic aneurysm metabolic behavior on positron emission tomography scan, 
aortic mechanical properties on echocardiography, or the presence of specific biomarkers. ${ }^{4-7}$

In our practice, we have recommended annual imaging with magnetic resonance imaging (MRI) to assess aortic size in patients with conotruncal abnormalities who are found to have aortic dimensions greater than $5 \mathrm{~cm}$ on echo. If the patient is unable to have an MRI, we recommend 1-time computed tomography (CT) angiogram to assess aortic dimension. If the patient has similar measurements on echocardiogram, follow-up with annual echocardiography is recommended with repeat CT angiogram only if there is significant change in aortic measurement by echocardiography. Patients who are thought to have rapid expansion of aortic dimension or who have other risk factors for aortic catastrophe warrant more frequent $\mathrm{CT}$ angiography. We recommend surgical referral for aortic enlargement when the aorta is $5.5 \mathrm{~cm}$ or larger if the patient has no other indication for surgery. After multidisciplinary review, most will be surgical but some may be managed expectantly. If the patient is referred to surgery for a nonaortic indication, discussion regarding risks and benefits of aortic replacement or reduction should be undertaken when the aorta is $4.5 \mathrm{~cm}$ or larger.

\section{References}

1. Coady MA, Rizzo JA, Hammond GL, Mandapati D, Darr U, Kopf GS, et al. What is the appropriate size criterion for resection of thoracic aortic aneurysms? J Thorac Cardiovasc Surg. 1997:113:476-910.

2. Vricella L. Nonsyndromic proximal aortic aneurysms: What size matters? J Thorac Cardiovas Surg. 2017;154:207-9.

3. Stulak JM, Dearani JA, Burkhart HM, Sundt TM, Connolly HM, Schaff HV. Does the dilated ascending aorta in an adult with congenital heart disease require intervention? J Thorac Cardiovasc Surg. 2010;140:S52-7.

4. Elefteriades JA. Indications for aortic replacement. J Thorac Cardiovas Surg. 2010;140:S5-9; discussion S45-51.

5. Reeps C, Essler M, Pelisek J, Seidl S, Eckstein HH, Krause BJ. Increased 18F-fluorodeoxyglucose uptake in abdominal aortic aneurysms in positron emission/ computed tomography is associated with inflammation, aortic wall instability, and acute symptoms. J Vasc Surg. 2008;48:417-23.

6. Koullias G, Modak R, Tranquilli M, Korkolis DP, Barash P, Elefteriades JA. Mechanical deterioration underlies malignant behavior of aneurysmal human ascending aorta. J Thorac Cardiovasc Surg. 2005;130:677-83.

7. Wang Y, Barbacioru CC, Shiffman D, Balasubramanian S, Iakoubova O, Tranquilli M, et al. Gene expression signature in peripheral blood detects thoracic aortic aneurysm. PLoS ONE. 2007;2:e1050. 